\title{
Development of a steady-state oral microbial biofilm community using the constant-depth film fermenter
}

\author{
Sarah L. Kinniment, ${ }^{1}$ Julian W. T. Wimpenny, ${ }^{1}$ David Adams ${ }^{2}$ \\ and Philip D. Marsh ${ }^{3}$
}

Author for correspondence: Julian W. T. Wimpenny. Tel: +44 1222874974.

e-mail:sabjw@cardiff.ac.uk

1 School of Pure and Applied Biology, University of Wales College of Cardiff, Cardiff CF1 3TL, UK

2 Department of Basic Dental Science, University of Wales College of Medicine, Cardiff CF4 4XY, UK

3 Centre for Applied Microbiology and Research, Salisbury SP4 0JG, UK

\begin{abstract}
The complexity of biofilm communities like dental plaque suggests that laboratory model biofilm growth systems may help to understand their structure and function. This study describes the use of a constant-depth film fermenter (CDFF) to investigate biofilm formation by a nine-membered community of oral bacteria. The community was grown to steady state in a chemostat incubated anaerobically. The chemostat output was fed into the CDFF incubated aerobically. Viable counts for each species from the chemostat and the CDFF at steady state showed major differences; however, all nine organisms were present under both conditions. There was evidence of succession during biofilm formation with obligately anaerobic species only establishing after several days. A steady-state biofilm community was achieved which remained stable over time. Electron microscopy showed evidence of spatial differentiation with what appeared to be Neisseria subflava dominant near the upper surface and Fusobacterium nucleatum largely confined to the middle portion.
\end{abstract}

Keywords: steady state, biofilm, community, oral, growth

\section{INTRODUCTION}

Biofilm is a microbial community that forms at a phase interface. Whilst most such sites can provide a niche for biofilm formation, the commonest is the solid-water interface. Even here, biofilms vary to an extraordinary degree. They may exist as monolayers of cells, or as thick gelatinous structures. They may be smooth and regular or highly irregular heterogeneous systems containing organic and inorganic matter and penetrated by pores or passages through which the aqueous phase can flow (Wilderer \& Characklis, 1989). The majority of natural biofilms, however, are complex communities consisting of a range of microbial types either attached to a conditioning film at the solid surface or embedded in a polysaccharide matrix produced by some of the species that make up the community.

Biofilm can be studied as the natural system in situ or it can be allowed to develop under controlled conditions in the laboratory. The use of laboratory model systems can be

Abbreviations: CDFF, constant-depth film fermenter; PTFE, polytetrafluoroethylene; TEM, transmission electron microscopy. recommended if they can provide unequivocal results which throw significant light on at least some aspects of the natural material.

Numerous different biofilm model systems exist. These have been reviewed by, among others, Characklis (1988, 1989), Peters \& Wimpenny (1988a), Gilbert \& Allison (1993) and Wimpenny et al. (1993). Some of the criteria that should apply to an appropriate biofilm model are as follows. It should be sterilizable and must allow the aseptic removal of samples which should be as discrete, representative, and as reproducible as possible. Also the fermenter should be capable of using any substratum material and of producing large numbers of separate film samples to allow the statistical reproducibility of experimental results to be assessed. Removal of the sample together with substratum should be possible, to avoid disturbance of the structure of the film. Ideally the system should generate biofilm under conditions that approximate to a steady state.

The virtue of such open systems has clearly been demonstrated by the chemostat and other continuous culture devices. A biological system at steady state has eliminated time as a variable. Steady states can be 
maintained, often for very long time periods. Against this constant background, parameters of interest can be altered and, by observing changes, unequivocal cause-and-effect relationships can be determined. One way to obtain a steady-state biofilm is to allow it to proliferate to a preset depth after which further accumulation is removed, in the end maintaining a constant geometry (Atkinson \& Fowler, 1974).

All the above criteria are met using the constant-depth film fermenter (CDFF) developed by Coombe et al. (1984), Peters (1988), Peters \& Wimpenny (1988b) and Wimpenny et al. (1993). In this device cells attach to the substratum surface and proliferate to fill a predetermined recessed space above the plug surface. Excess material is removed from the upper surface of the film using a scraper blade. After a period the film becomes 'steady state' as judged by protein content and viable count.

The CDFF has been used to establish steady-state monocultures of Pseudomonas aeruginosa (Kinniment \& Wimpenny, 1990, 1992; Wimpenny et al., 1993). However, a more interesting application would be to establish a steady-state community containing a number of different species.

Dental plaque is the general term used to describe the complex microbial community embedded in a matrix of polymers found on a tooth surface. The majority of plaque is associated with protected and stagnant regions of tooth surfaces such as fissures, approximal regions and the gingival crevice (Marsh \& Martin, 1992). Problems are encountered when studying the microbial communities at such sites because of the basic difficulties in collecting samples. Even if the majority of the microorganisms are removed when sampling, such treatment destroys the spatial heterogeneity of the biofilm, reducing the value of the results that can be obtained. There are advantages, therefore, in studying model plaque-related systems in the laboratory. The system selected here is an oral community similar to one developed by Bradshaw et al. (1989a, b, 1990) and Marsh \& Bradshaw (1993), which was established both as a homogeneous system in a chemostat and by growing on hydroxyapatite tiles suspended in a chemostat. The nine organisms that comprise the community are all associated with dental plaque formation in health and disease and consist of a mixture of aerobic, anaerobic and aerotolerant species.

The aim of the present study was to develop a stable and reproducible biofilm model from a defined inoculum of nine plaque bacteria, using the CDFF. The development of a steady-state biofilm is described together with preliminary studies on the spatial distribution of bacteria within it.

\section{METHODS}

Organisms. The nine strains used in this study were Neisseria subflava A1078, Veillonella dispar ATCC 17748, Lactobacillus casei AC 413, Fusobacterium nucleatum ATCC 10953, Actinomyces viscosus WVU 627, Porpbyromonas gingivalis W50, Streptococcus oralis EF 186, Streptococcus gordonii NCTC 7865 and Streptococcus mutans R9.
Growth medium. The growth medium was a complex medium in which a model glycoprotein (hog gastric mucin) was used as the major carbon source (Bradshaw et al., 1990). The composition $\left(\mathrm{g} \mathrm{l}^{-1}\right)$ was: porcine gastric mucin (Sigma), $2 \cdot 5 ; \mathrm{KCl}$, 2.5 ; proteose peptone (Lab-M), 2; yeast extract (Difco), 1; trypticase peptone (BBL), 1; cysteine hydrochloride, $0 \cdot 1$; haemin, 0.001 .

Chemostat inoculation and growth conditions. The chemostat (LH 500 series II, LH Engineering) had a working volume of $500 \mathrm{ml}$. Initially, approximately $250 \mathrm{ml}$ sterile medium was added to the vessel. A mixed culture of the nine strains listed above, stored in glass vials at $-70{ }^{\circ} \mathrm{C}$ (Bradshaw et al., $1989 \mathrm{~b})$, was then used to inoculate the chemostat. Medium was then pumped in at a rate of $15 \mathrm{ml} \mathrm{h}^{-1}$ until the working volume of $500 \mathrm{ml}$ was reached; the flow rate was then altered to $50 \mathrm{ml}$ $\mathrm{h}^{-1}$ giving a dilution rate of $0 \cdot 1 \mathrm{~h}^{-1}$. The chemostat was operated under a gas phase of $5 \%(\mathrm{v} / \mathrm{v}) \mathrm{CO}_{2}$ in $\mathrm{N}_{2}$, the temperature was kept at a constant $37^{\circ} \mathrm{C}$, and the $\mathrm{pH}$ was maintained at 7.0 \pm 0.1 by the automatic addition of $2 \mathrm{M} \mathrm{NaOH}$.

Inoculation of the CDFF. The output from the steady-state chemostat culture having a mean generation time of $6.93 \mathrm{~h}$ $\left(D=0 \cdot 1 \mathrm{~h}^{-1}\right)$ was used to inoculate the CDFF over a period of $8 \mathrm{~h}$. During this time, sterile fresh medium was also pumped into the CDFF at a rate of $50 \mathrm{ml} \mathrm{h}^{-1}$. After $8 \mathrm{~h}$ the chemostat output was disconnected, leaving only fresh medium entering the CDFF.

Operation of the CDFF. The CDFF used was the same as that described by Wimpenny et al. (1993). Biofilms were allowed to grow on $4.75 \mathrm{~mm}$ diameter polytetrafluoroethylene (PTFE) plugs located in 15 PTFE sample pans which were inserted into a rotatable stainless-steel turntable. Each pan contained six plugs which were recessed to a depth of $300 \mu \mathrm{m}$. The biofilm developed until it reached this thickness and was maintained so by the scraper bar. The turntable rotated at 3 r.p.m. and the fermenter was operated at $37^{\circ} \mathrm{C}$, under a gas phase of air with a flow rate of $250 \mathrm{ml} \mathrm{min}^{-1}$. The medium flow rate was $50 \mathrm{ml}$ $\mathrm{h}^{-1}$.

The composition of the medium was the same as that used in the chemostat. Medium dripped onto the turntable just in front of one scraper blade, where it was then distributed over the sample pans. Waste medium flowed off the turntable and out of an outlet port in the base plate of the fermenter into a collection vessel beneath. Using sterilizable stainless-steel tools, samples were removed aseptically over time through a sample port in the top plate of the fermenter. These were then assessed for viable counts and protein concentration or by electron microscopy.

\section{Estimation of biomass}

Chemostat viable counts. Samples were taken periodically, serially diluted in medium and then plated out on a range of selective and non-selective media, as previously described by McKee et al. (1985), Bradshaw et al. (1989b) and Bradshaw (1992). Blood agar was used for counting $N$. subflava when incubated aerobically and total viable counts when incubated anaerobically, and contained in $\mathrm{l}^{-1}$ : Columbia Agar Base (Oxoid), 39; extra agar Bacto-agar (Difco), 5; and horse blood (Oxoid), $7 \%$ (v/v). Vancomycin blood agar was used to count the Gram-negative anaerobes and contained in $\mathrm{g} \mathrm{l}^{-1}$ : Blood Agar Base No. 2 (Oxoid), 40; vancomycin hydrochloride (Sigma), 0.0025; and horse blood (Oxoid), $7 \%$ (v/v). Tryptone yeast cystine medium (TYC, Lab-M; $98 \mathrm{~g} \mathrm{l}^{-1}$ ) was used for enumerating the streptococci species. Tryptone yeast cystine sucrose bacitracin medium (Van Palenstein-Helderman et al., 1983) was used to enumerate S. mutans, and contained, in addition to TYC, $15 \%(\mathrm{w} / \mathrm{v})$ extra sucrose and $0 \cdot 1$ unit bacitracin $\mathrm{ml}^{-1}$ (Sigma). Cadmium fluorideacriflavin-tellurite medium was used to identify $A$. viscosus 
(Zylber \& Jordan, 1982). It contained in $\mathrm{g}^{\mathbf{- 1}}$ : trypticase soy broth (BBL, Microbiology Systems), 30; glucose, 5; agar, 15; cadmium sulphate, 0.013 ; sodium fluoride, 0.08 ; neutral acriflavin, 0.0012 ; potassium tellurite, 0.0025 ; basic fuchsin, 0.00025 ; and $5 \%(\mathrm{v} / \mathrm{v})$ horse blood (Oxoid).

CDFF viable counts. A sample pan was removed from the fermenter and, using sterile forceps, plugs were carefully pushed out of the pan with the film still intact on the surface. Biofilm was dispersed by vortex mixing three individual or three pairs of sample plugs separately in $10 \mathrm{ml}$ fresh medium for $30 \mathrm{~s}$. Aliquots were plated out and enumerated on the range of selective media described above and the geometric mean and log standard deviation for each time point was calculated.

CDFF protein estimation. This was determined for each plug using a modified Lowry method as described before by Kinniment \& Wimpenny (1992). Protein on each plug was assayed separately by boiling in $0.5 \mathrm{ml} 1 \mathrm{M} \mathrm{NaOH}$ for $5 \mathrm{~min} ; 0.125 \mathrm{ml}$ of each of these subsamples was then diluted in $0.375 \mathrm{ml} 1 \mathrm{M} \mathrm{NaOH}$. A solution $(2.5 \mathrm{ml})$ containing $96 \mathrm{ml} 5 \%(\mathrm{w} / \mathrm{v}) \mathrm{Na}_{2} \mathrm{CO}_{3}$ and $4 \mathrm{ml}$ $0.5 \% \mathrm{CuSO}_{4} .5 \mathrm{H}_{2} \mathrm{O}$ in $1 \%(\mathrm{w} / \mathrm{v})$ sodium potassium tartrate was added to the boiled and cooled samples. After $10 \mathrm{~min}$, $0.5 \mathrm{ml}$ diluted Folin-Ciocalteu reagent was rapidly added to the tube, which was shaken immediately and left for $30 \mathrm{~min}$ before the $A_{750}$ was measured (Pye-Unicam SP1800 spectrophotometer). Protein standards containing 5-150 mg protein (bovine albumin fraction five, $\mathrm{BDH}$ ) were prepared each time the assay was performed. The absorbance values for the biofilm samples were then read against these standard curves. The mean protein value and standard deviation of the subsamples were then calculated for each time point.

Electron microscopy. Transmission electron microscopy (TEM) was carried out using standard methods. Sample plugs, carefully pushed out of the pans with intact film attached, were fixed by immersing in $3 \%(\mathrm{v} / \mathrm{v})$ glutaraldehyde in phosphate buffer for $3 \mathrm{~h}$ at $4{ }^{\circ} \mathrm{C}$. They were rinsed in fresh buffer overnight at $4{ }^{\circ} \mathrm{C}$ before post-fixation in Millonigs buffered osmium tetroxide for $1 \mathrm{~h}$ at $4{ }^{\circ} \mathrm{C}$. The samples were then dehydrated by placing them successively in $50 \%(\mathrm{v} / \mathrm{v})$ ethanol for $10 \mathrm{~min}$, $70 \%$ for $15 \mathrm{~min}, 90 \%$ for $15 \mathrm{~min}$ and $100 \%$ for $30 \mathrm{~min}$, all at $4{ }^{\circ} \mathrm{C}$. The samples were then put into LR White resin at room temperature overnight. The LR White resin was changed, and samples were left to rotate for $8 \mathrm{~h}$ in a fresh batch of resin. Fresh resin was then placed in aluminium moulds. Sample plugs were carefully trimmed down with a scalpel so that the total height of the substratum plug plus biofilm was $<3 \mathrm{~mm}$ and placed film side up in the resin. The resin was then polymerized anaerobically at $60^{\circ} \mathrm{C}$ for $24 \mathrm{~h}$ under a $\mathrm{CO}_{2}$ atmosphere. After polymerization was complete, the remains of the PTFE plugs were carefully removed from the films, leaving the intact film embedded in the polymerized resin. The recesses left by the plugs were then filled with fresh LR White resin and the polymerization process was completed again. The biofilm was now completely enclosed by the resin.

Ultrathin $90 \mathrm{~nm}$ sections were then cut vertically through the biofilm using an LKB Main Unit 8800 Ultrotome III, so that the entire profile from the base to the surface of the biofilm could be viewed. Sections were picked up onto copper grids, then stained with lead citrate and uranyl acetate (Reynolds, 1963) and viewed in a Jeol-100S transmission electron microscope.

Statistical methods. Mean bacterial numbers were compared by analysis of variance (ANOVA) using $\log _{10}$ transformed data. Assumptions of ANOVA were confirmed on each occasion. Differences in mean values for chemostat and film fermenter runs were determined by minimum significant difference using the Tukey-Kramer test. All analyses were performed using Minitab Release 9.2. Film fermenter runs were compared using the Kruskat-Wallis test to confirm significant difference between data sets.

\section{RESULTS}

\section{Growth of the oral community}

The chemostat was operated under anaerobic conditions. After inoculation, viable counts varied over the first $100 \mathrm{~h}$ but by $150 \mathrm{~h}$ the system appeared to have reached a steady state. In particular, the numbers of $N$. subflava and $S$. mutans both rose then fell by approximately two and one orders of magnitude, respectively. Conversely, counts of $P$. gingivalis fell, then rose by one order of magnitude, before reaching steady state. Total counts reached a maximum, about $2-3 \times 10^{8}$ c.f.u. $\mathrm{ml}^{-1}$, after $50 \mathrm{~h}$ and remained stable thereafter (Fig. 1). The dominant species at steady state was $F$. nucleatum whilst the least numerous was S. mutans (Figs 1 and 3; Table 1). Analysis of all chemostat runs showed that no significant variation existed between the steady states of the bacterial community $(P=0.621)$.

The output from the chemostat was used to inoculate the CDFF for a period of $8 \mathrm{~h}$ to allow cell attachment. The $\mathrm{CDFF}$ was incubated aerobically to simulate conditions in the mouth. Three separate fermenter runs were carried out. The longest of these was for 5 weeks or some $840 \mathrm{~h}$. Steady states were reached for total viable counts after about $100 \mathrm{~h}$, and in terms of protein by $250 \mathrm{~h}$ (Fig. 2a).

Individual species behaved differently. The aerobic $N$. subflava, already present at high levels, reached a steady state at $200 \mathrm{~h}$ whilst $A$. viscosus and $L$. casei reached peak values at $280 \mathrm{~h}$ but fell towards a lower steady state by about 400 h (Fig. 2b).

Numbers of all the streptococci reached a plateau after about $150 \mathrm{~h}$. Of the three, $S$. mutans was present in lowest



Fig. 1. Growth of the oral community in the chemostat. The chemostat had a working volume of 0.51 and was operated anaerobically at a dilution rate of $0.1 \mathrm{~h}^{-1}$. Samples were withdrawn at stated intervals and viable counts were determined on appropriate selective media as described in the Methods section. $\downarrow, N$. subflava; $\triangle, A$. viscosus; $4, L$. casei; $O$, S. oralis; $\square$, S. gordonii; $\Delta$, S. mutans; $\square, V$. dispar;,$P$. gingivalis; $\diamond, F$. nucleatum; $\nabla$, total count. 
Table 1. Reproducibility of the chemostat community at steady state

Viable counts are shown for each of the nine organisms present. Data are based on six separate samples from six different experiments.

\begin{tabular}{|c|c|c|c|c|c|c|}
\hline Organism & $\begin{array}{c}\text { Mean } \\
\text { viable cell } \\
\text { numbers } \\
\left(\log _{10} \text { c.f.u. }\right. \\
\left.\text { ml l-1) }^{-1}\right)\end{array}$ & $\begin{array}{c}\text { Range of } \\
\text { viable cell } \\
\text { numbers } \\
\left(\log _{10} \text { c.f.u. }\right. \\
\left.\text { ml }^{-1}\right)\end{array}$ & $\log _{10}$ SD & $\begin{array}{c}\text { Mean (percentage } \\
\text { of total) }\end{array}$ & $\begin{array}{c}\text { Range (percentage } \\
\text { of total) }\end{array}$ & SD $(\%)$ \\
\hline N. subflava & $5 \cdot 33$ & $5 \cdot 00-5 \cdot 71$ & $0 \cdot 25$ & $0 \cdot 18$ & $0.074-0.48$ & $0 \cdot 15$ \\
\hline A. viscosus & 6.06 & $5 \cdot 32-6 \cdot 50$ & 0.45 & 0.98 & $0 \cdot 20-2 \cdot 14$ & 0.67 \\
\hline L. casei & $5 \cdot 54$ & $4.83-5.96$ & $0 \cdot 38$ & $0 \cdot 24$ & $0.045-0.40$ & $0 \cdot 16$ \\
\hline S. oralis & 6.81 & $5 \cdot 63-7 \cdot 41$ & $0 \cdot 68$ & $8 \cdot 70$ & $0 \cdot 14-15 \cdot 33$ & 6.49 \\
\hline S. gordonii & $7 \cdot 27$ & $6.63-7.95$ & 0.58 & $19 \cdot 85$ & $3 \cdot 16-39 \cdot 4$ & $16 \cdot 62$ \\
\hline S. mutans & $4 \cdot 85$ & $4 \cdot 49-5 \cdot 77$ & $0 \cdot 50$ & $0 \cdot 1$ & $0 \cdot 02-0.44$ & $0 \cdot 17$ \\
\hline$V$. dispar & 6.89 & $6 \cdot 30-7 \cdot 50$ & 0.40 & $6 \cdot 21$ & $1 \cdot 90-10 \cdot 72$ & $3 \cdot 31$ \\
\hline P. gingivalis & $7 \cdot 06$ & $6 \cdot 27-7 \cdot 45$ & $0 \cdot 49$ & $12 \cdot 99$ & $1 \cdot 11-30 \cdot 0$ & $11 \cdot 61$ \\
\hline F. nucleatum & $7 \cdot 85$ & $7 \cdot 56-8 \cdot 17$ & $0 \cdot 22$ & $50 \cdot 18$ & $34 \cdot 7-67 \cdot 0$ & $12 \cdot 73$ \\
\hline Total & 8.09 & $7 \cdot 80-8 \cdot 47$ & $0 \cdot 23$ & - & - & - \\
\hline
\end{tabular}

numbers. $S$. gordonii and $S$. oralis were detected at approximately equal levels at steady state (Fig. 2c).

The anaerobes showed the most interesting behaviour during biofilm development. As might be expected when exposed to the aerobic conditions in the CDFF, all of these fell to very low numbers. $F$. nucleatum and $V$. dispar were detectable at about $10^{4} \mathrm{ml}^{-1}$. Their numbers then rose to reach a peak at $70-90 \mathrm{~h}$. F. nucleatum remained high thereafter whilst the $V$. dispar fell to a steady state 2 logs lower than its peak value, after about $500 \mathrm{~h}$. Even more dramatic was the behaviour of $P$. gingivalis. Its numbers were only just detectable $\left(<10^{3} \mathrm{ml}^{-1}\right)$ for the first $120 \mathrm{~h}$. They then rose rapidly, reaching a steady state value of about $6 \times 10^{7}$ c.f.u. per plug by 250 h (Fig. $2 \mathrm{~d}$ ). Three CDFF runs were performed in all. Whilst the steady state in any one experiment was reasonably stable, as is clear from Fig. 2, biofilm community reproducibility between runs was more variable and analysis indicated some major differences between the bacterial communities in each of these systems. To indicate the degree of reproducibility between experiments, all the data are summarized in terms of mean numbers and range of data. These are also expressed as a percentage of the total viable counts (Table 2).

The film fermenter experiment which was run for the longest duration was selected for comparison with the chemostat (Fig. 3).

Although $S$. mutans and $L$. case $i$ were minor components in both, the chemostat was dominated by $F$. nucleatum, whereas $P$. gingivalis and $N$. subflava predominated in the biofilm.

The data confirm that the dominant members of the biofilm community were $N$. subflava and $P$. gingivalis. Next most important numerically were $F$. nucleatum, $S$. gordonii and $S$.oralis. $S$. mutans under these conditions accounts for only about $1-2 \%$ of the biofilm population. $V$. dispar, $A$. viscosus and $L$. case $i$ were only minor components of the film, usually accounting for no more than $1 \%$ each of the population.

\section{Structure of the steady-state biofilm}

The biofilm was prepared for TEM. Serial sections were generated and photographed. These, together with enlargements of selected areas near the upper and lower surfaces and in the middle of the biofilm, are shown in Fig. 4. Although individual species cannot be recognized with certainty, the numbers of ' $k$ idney'-shaped cocci near the upper surface suggest that these are $N$. subflava, whilst towards the middle and in the lower half of the biofilm the anaerobic $F$. nucleatum cells are recognized by their characteristic long tapering rod-shaped morphology.

\section{DISCUSSION}

The experimental set-up described in this paper has a number of interesting aspects. First of all, two steady-state devices, each operating under different conditions, were coupled together. The community in the chemostat reached a steady state under anaerobic conditions. Here the dominant populations were mainly anaerobic, including $F$. nucleatum, $P$. gingivalis and $V$. dispar. Under these conditions, N. subflava, $S$. mutans and $L$. casei also reached steady-state conditions albeit at a low level. This was a similar picture to that observed with a 10 -membered community in a chemostat (Bradshaw et al., 1989a).

The transition to an aerobic film fermenter, intended to be more representative of conditions during plaque formation within the mouth, posed a severe stress problem for the anaerobic members of the community. This stress must also exist in the oral environment and as they survive there, they also survived in the CDFF. In spite of the aerobic atmosphere in the CDFF, the obligate anaerobe $P$. 

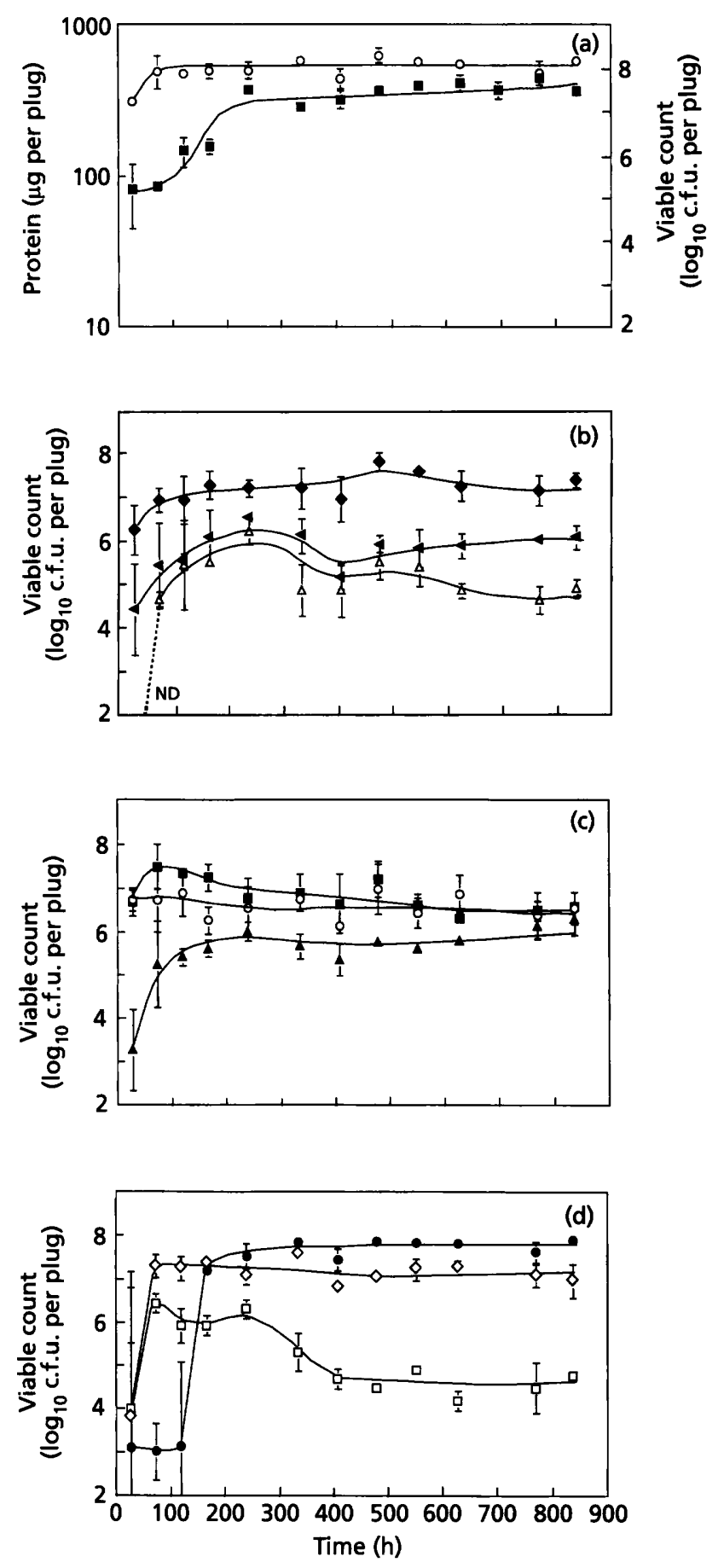

Fig. 2. Growth of the biofilm. The CDFF was operated aerobically, the medium flow rate was $50 \mathrm{ml} \mathrm{h}^{-1}$ and the pans were rotated at 3 r.p.m. Film plugs were recessed by $300 \mu \mathrm{m}$ and individual film pans with their six film samples were removed at stated intervals. Biofilm was homogenized and total protein and viable counts for each species were determined as described in the Methods section. Results presented here are for a single run. (a) Total viable count $(O)$ and protein estimation ( $(\mathrm{D})$. (b-d) Growth of each organism within the biofilm. Each point is the geometric mean of the viable count from three separate plugs treated independently. The error bars are the $\log _{10}$ standard deviations of these three counts. (b) $\downarrow, N$. subflava; $\triangle, A$. viscosus; $\perp, L$. casei. (c) $O, S$. oralis; $\square$, gordonii; $\triangle$, S. mutans. (d) $\square, V$. dispar; $O, P$. gingivalis; $\diamond$, F. nucleatum. gingivalis eventually became the most common organism in the biofilm. N. subflava with an oxidative type of metabolism emerged as the second most common member of the community and electron micrographs suggest that this organism occupied the upper, more aerobic, layers of the biofilm.

The film fermenter generated a steady-state biofilm. The total viable count reached steady state first, even though the levels of individual species within the film were not constant at this stage. Protein concentrations became constant after about $240 \mathrm{~h}$ and remained this way for the duration of the experiment. However there was some variation in the time taken $(4-500 \mathrm{~h})$ for particular species to reach a steady state, but all did so eventually.

The steady state represented a 'climax' population in ecological terms. The period before this climax was itself interesting since it demonstrated the successional changes that took place as a function of time. The obligate anaerobes showed the most obvious changes. Counts for all three species fell rapidly at first, in some cases close to minimum detectable levels. They recovered at different rates, with levels of the Fusobacterium and the Veillonella increasing most quickly, and the Porphyromonas more slowly yet achieving the highest steady-state value of the three after about $200 \mathrm{~h}$.

$N$. subflava quickly became a dominant member of the community together with $S$. oralis and $S$. gordonii, the three constituting classical dental plaque pioneer species. $A$. viscosus and $L$. case $i$ and to a lesser extent the three streptococci showed minor variations in viable count before reaching steady state. The aerobic environment was probably responsible for the rise in total numbers and proportion of $N$. subflava within the community during growth in the CDFF. The utilization of oxygen by the higher numbers of this aerobe would maintain anaerobiosis and a low redox potential within the biofilm, providing niches for the growth of the obligately anaerobic species.

The question of reproducibility must be discussed. Three CDFF runs were carried out; although each reached a steady state there is a significant variation between runs $(P<0.001)$. In other words, it is difficult to replicate exactly the community of nine species within the biofilm. It seems at least possible that an interacting system of nine separate dynamic entities could generate a number of different steady states, each of which could 'satisfy' the demands of the system. One reason for variability might be that small mutations take place continuously in any growing cell population. This is most clearly seen in prolonged steady-state culture systems (see, for example, Powell, 1958). Such variation amongst a community of nine different species could clearly alter the balance of the population.

The biofilm is easy to remove from the PTFE substratum and then to fix and embed for electron microscopy. TEM was used to generate a full width set of serial sections. These indicate that $N$. subflava appears to be located in the upper parts of the biofilm whilst $F$. nucleatum appears near the base. Other organisms cannot readily be identified 
Table 2. Reproducibility of the biofilm community at steady state

Viable counts are shown for each of the nine organisms present. Data are based on three separate samples from three different experiments.

\begin{tabular}{|c|c|c|c|c|}
\hline Organism & $\begin{array}{c}\text { Mean viable cell } \\
\text { numbers } \\
\left(\log _{10} \text { c.f.u. per plug) }\right.\end{array}$ & $\begin{array}{c}\text { Range of viable } \\
\text { cell numbers } \\
\left(\log _{10} \text { c.f.u. per plug) }\right.\end{array}$ & Mean (\%) & Range (\%) \\
\hline N. subflava & $7 \cdot 74$ & $7 \cdot 36-8 \cdot 46$ & $40 \cdot 9$ & $24 \cdot 0-65 \cdot 6$ \\
\hline A. viscosus & $5 \cdot 24$ & $4 \cdot 73-5 \cdot 96$ & $0 \cdot 20$ & $0.09-0.39$ \\
\hline L. casei & $5 \cdot 62$ & $5 \cdot 51-5 \cdot 92$ & $0 \cdot 48$ & $0 \cdot 08-0 \cdot 84$ \\
\hline S. mutans & $6 \cdot 12$ & $5 \cdot 51-7 \cdot 04$ & $1 \cdot 37$ & $0.53-2.85$ \\
\hline$V$. dispar & $5 \cdot 45$ & $4 \cdot 68-6 \cdot 25$ & $1 \cdot 04$ & $0 \cdot 36-2.61$ \\
\hline$P$. gingivalis & $7 \cdot 63$ & $7 \cdot 24-7 \cdot 88$ & $32 \cdot 13$ & $17 \cdot 91-52.28$ \\
\hline F. nucleatum & $7 \cdot 18$ & $7 \cdot 14-7 \cdot 26$ & $14 \cdot 05$ & $3 \cdot 29-25 \cdot 45$ \\
\hline Total & $8 \cdot 20$ & $7 \cdot 87-8.66$ & - & - \\
\hline
\end{tabular}

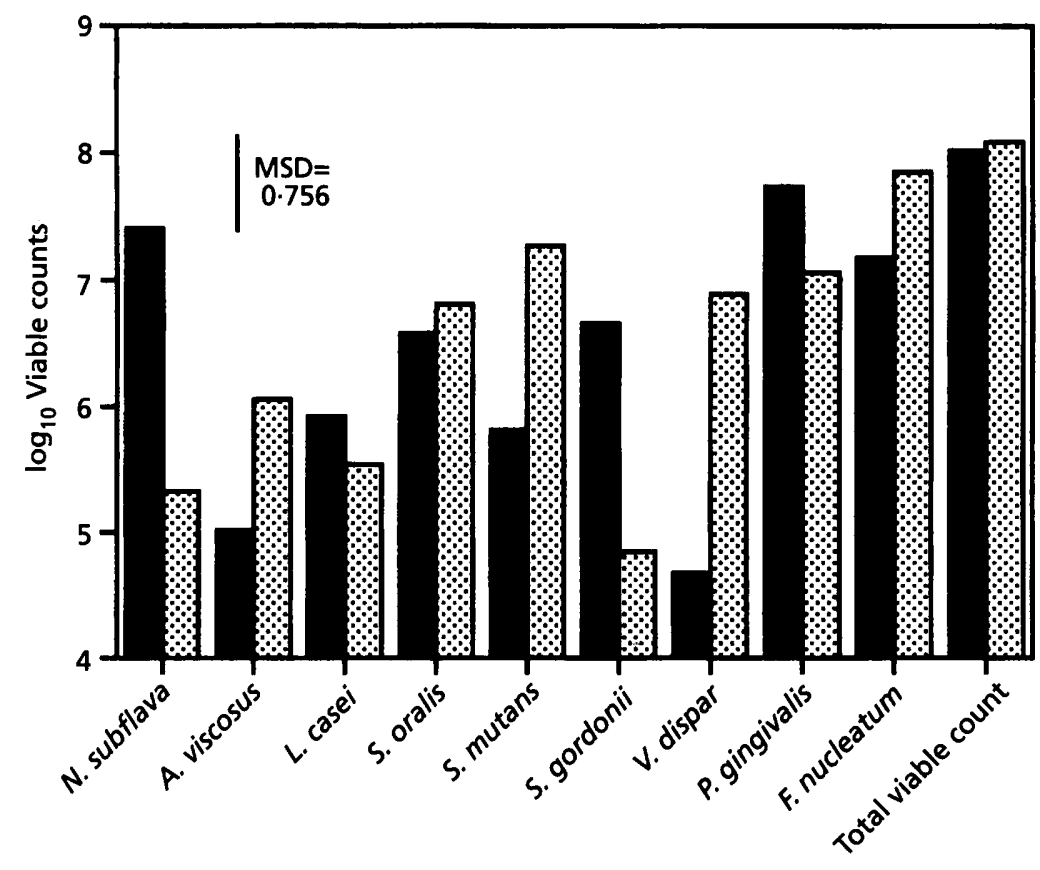

Fig. 3. Steady-state values of the oral
community in the chemostat compared to
that in the biofilm. The biofilm data shown
are the mean of data from film fermenter
run $3(\square)$; the chemostat data shown are
the mean of six experiments (⿴囗大). Minimum
significant difference (MSD) at $P=0.05$
enables comparison between individual
bacterial species but not for total viable
counts. Statistically there is no significant
difference between numbers in the
chemostat and in the CDFF for $L$. casei, $S$.
oralis, $P$. gingivalis and $F$. nucleatum.

solely on the basis of their cell morphology and gold- or fluorescent-labelled antibodies are being developed to study the biofilm structure. In addition, TEM will help to reveal the existence of structures within the biofilm, for example 'corn cob' formations, pallisades and rosettes seen in natural dental plaque.

Although it is difficult to compare an in vitro model system with the in vivo situation, our system showed a number of similarities with phenomena that occur within human dental plaque. The CDFF allows a deep ( $300 \mu \mathrm{m}$ thick) biofilm to accumulate and therefore allows solute diffusion gradients to establish, leading to structural differentiation. Ritz (1969) showed that Neisseria are present in upper parts of natural plaque whilst Veillonella appear only near the base of the structure, a situation which is also suggested by results reported here.

The CDFF has a number of other virtues which it is planned to exploit with the nine-membered community in future studies. (i) Because of the dimensional reproducibility of each biofilm sample, it should be possible to deploy microelectrodes for $\mathrm{pH}$, oxygen, redox potential, etc. to profile gradients in these factors within the biofilm. (ii) The film sample can be freeze-sectioned either horizontally or vertically. This has been done to monitor viability and adenylate levels in a pseudomonad biofilm (Wimpenny et al., 1993). Vertical sections can be used for 


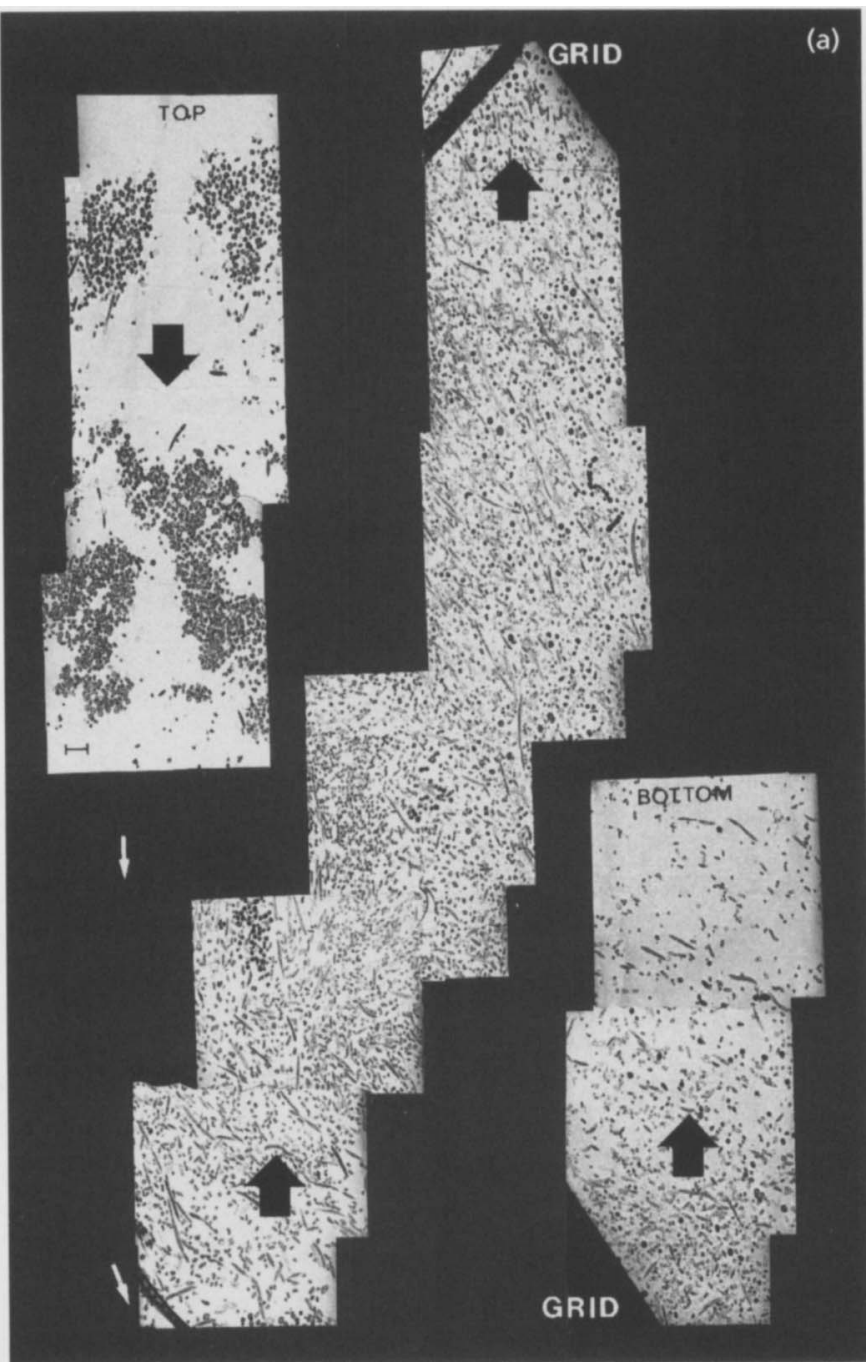

Fig. 4. (a) Transmission electron micrograph from the base to the surface of an oral biofilm community at steady state. Arrows indicate the direction of the image from top to bottom. Bar, $3 \mu \mathrm{m}$. (b) Enlargements of the surface, middle and base regions. Bars, $2 \mu \mathrm{m}$.

enzyme-histochemical or radioisotope estimations, whilst horizontal sections may also be used to assay chemical or biological components of the biofilm. In this way, the CDFF can be used to study factors important in determining the events that cause the plaque microflora to progress from having a commensal to a pathogenic relationship with the host.

\section{ACKNOWLEDGEMENTS}

This research was supported by grant MRC9114774 from the Medical Research Council of Great Britain, which we gratefully acknowledge. We would also like to express our gratitude to Carole Winters for help with the electron microscopy and to Caroline Perkins for carrying out the statistical analysis.
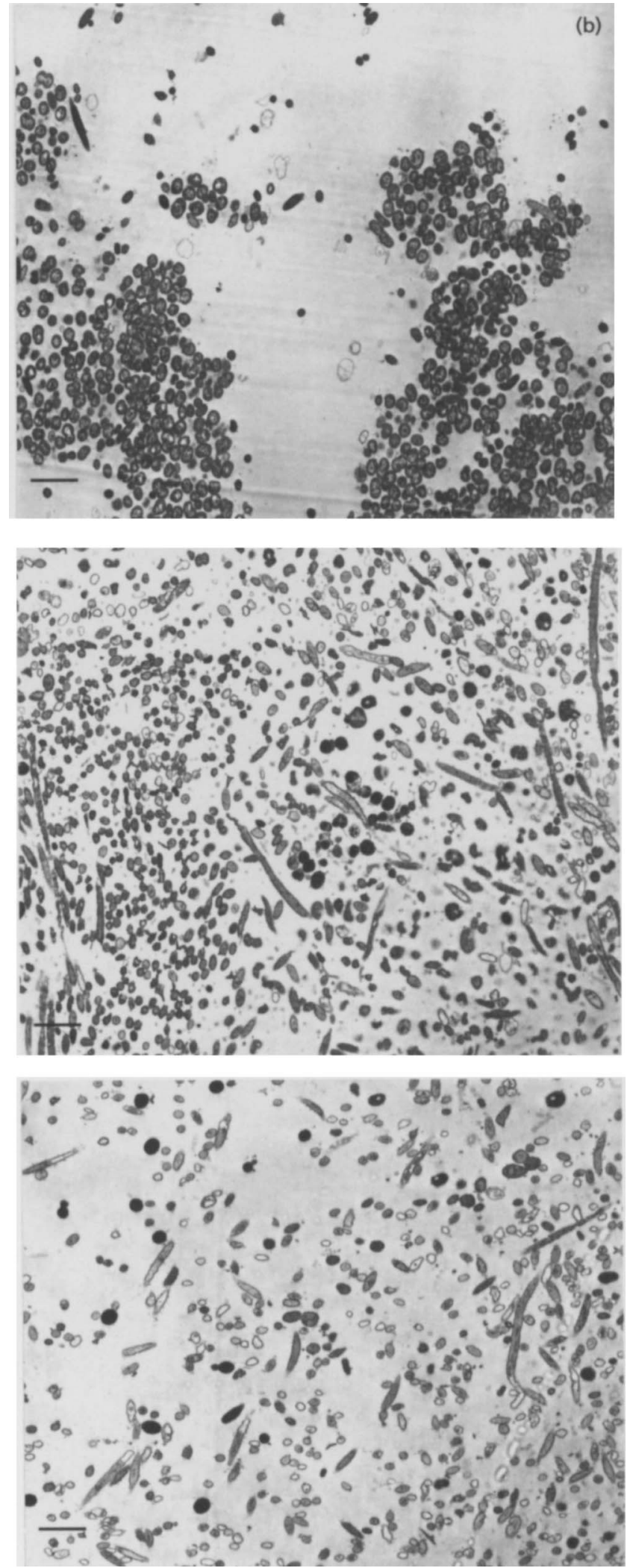

\section{REFERENCES}

Atkinson, B. \& Fowler, H. W. (1974). The significance of microbial film fermenters. Adv Biochem Eng 3, 224-277.

Bradshaw, D. J. (1992). Continuous culture modelling of environmental 
factors affecting the oral microflora. $\mathrm{PhD}$ thesis, Centre for Applied Microbiology and Research, Salisbury, UK.

Bradshaw, D. J., McKee, A. S. \& Marsh, P. D. (1989a). Effects of carbohydrate pulses and $\mathrm{pH}$ on population shifts within oral microbial communities in vitro. J Dent Res 68, 1298-1302.

Bradshaw, D. J., McKee, A. S. \& Marsh, P. D. (1989b). The use of defined inocula stored in liquid nitrogen for mixed culture chemostat studies. J Microbiol Methods 9, 123-128.

Bradshaw, D. J., McKee, A. S. \& Marsh, P. D. (1990). Prevention of population shifts in oral microbial communities in vitro by low fluoride concentrations. J Dent Res 69, 436-441.

Characklis, W. G. (1988). Model biofilm reactors. In $A$ Handbook of Laboratory Model Systems for Microbial Ecosystems, vol. 1, pp. 155-174. Edited by J. W. T. Wimpenny. Boca Raton, FL: CRC Press.

Characklis, W. G. (1989). Laboratory biofilm reactors. In Biofilms. Edited by W. G. Characklis \& K. C. Marshall. New York: John Wiley.

Coombe, R. A., Tatevossian, A. \& Wimpenny, J. W. T. (1984). Factors affecting the growth of thin film bacterial films in vitro. In Bacterial Adbesion and Preventive Dentistry, pp. 193-205. Edited by J. M. ten Cate, S. A. Leach \& J. Arends. Oxford: IRL Press.

Gilbert, P. \& Allison, D. G. (1993). Laboratory methods for biofilm production. In Microbial Biofilms: Formation and Control. Society for Applied Bacteriology Technical Series 30, pp. 29-49. Edited by S. P. Denyer, S. P. Gorman \& M. Sussman. Oxford: Blackwell Scientific.

Kinniment, S. L. \& Wimpenny, J.W. T. (1990). Biofilms and biocides. Int Biodeterior 26, 181-194.

Kinniment, S. L. \& Wimpenny, J. W. T. (1992). Measurements of the distribution of adenylate concentrations and adenylate energy charge across Pseudomonas aeruginosa biofilms. Appl Environ Microbiol 58, 1629-1635.

Marsh, P. D. \& Bradshaw, D. J. (1993). Microbiological effects of new agents in dentifrices for plaque control. Int Dent J 43, 399-406.

Marsh, P. D. \& Martin, M. (1992). Oral Microbiology, 3rd edn. London: Chapman \& Hall.
McKee, A. S., McDermid, A. S., Ellwood, D. C. \& Marsh, P. D. (1985). The establishment of reproducible, complex communities of oral bacteria in the chemostat using defined inocula. $J A p p l$ Bacteriol 59, 263-275.

Peters, A. C. (1988). A constant depth laboratory model film fermenter. $\mathrm{PhD}$ thesis, University College Cardiff, Cardiff, UK.

Peters, A. C. \& Wimpenny, J. W. T. (1988a). A constant depth laboratory film fermenter. In $A$ Handbook of Laboratory Model Systems for Microbial Ecosystems, vol. 1, pp. 175-195. Edited by J. W. T. Wimpenny. Boca Raton, FL: CRC Press.

Peters, A. C. \& Wimpenny, J. W. T. (1988b). A constant depth laboratory model film fermenter. Biotechnol Bioeng 32, 263-270.

Powell, E. O. (1958). Criteria for the growth of contaminants and mutants in continuous culture. J Gen Microbiol 18, 259-268.

Reynolds, E. S. (1963). The use of lead citrate at high $\mathrm{pH}$ as an electron opaque stain in electron microscopy. J Cell Biol 17, 208.

Ritz, H. L. (1969). Fluorescent antibody staining of neisseria, streptococcus and veillonella in frozen sections of human dental plaque. Arch Oral Biol 14, 1073-1083.

Van Palenstein-Helderman, W. H., ljsseldijk, M. \& Huis In 't Veld, J. H. J. (1983). A selective medium for the two major subgroups of the bacterium Streptococcus mutans isolated from human dental plaque and saliva. Arcb Oral Biol 28, 599-603.

Wilderer, P. A. \& Characklis, W. G. (1989). Structure and function of biofilms. In Structure and Function of Biofilms, Pp. 5-17. Edited by W. G. Characklis \& P. A. Wilderer. Chichester: John Wiley.

Wimpenny, J. W. T., Kinniment, S. L. \& Scourfield, M. A. (1993). The physiology and biochemistry of biofilm. In Microbial Biofilms: Formation and Control. Society for Applied Bacteriology Tecbnical Series 30, pp. 51-94. Edited by S. P. Denyer, S. P. Gorman \& M. Sussman. Oxford: Blackwell Scientific.

Zylber, L. J. \& Jordan, H. A. (1982). Development of a selective medium for detection and enumeration of Actinomyces viscosus and Actinomyces naeslundii in dental plaque. J Clin Microbiol 15, 253-259.

Received 13 November 1995; accepted 27 November 1995. 